\title{
BELIEVING IS SEEING: PARADIGMS AS A FOCAL POINT IN THE LEAN DISCOURSE
}

\author{
Samuel Korb ${ }^{1}$ and H. Glenn Ballard ${ }^{2}$
}

\begin{abstract}
In many ways, the transition from traditional modes of management thinking and behavior to Lean approaches is what Kuhn referred to as a "paradigm shift". Not only surface artifacts like behavior are different in a Lean organization - the most basic assumptions and patterns of thought are fundamentally different than those that have guided organizations for decades. The resulting paradigm gap between traditional thinkers and Lean thinkers may help to explain the conceptual disconnect between the two groups; the two have no common assumptions on which to base a productive dialogue about what degree of organizational excellence is possible. In this paper, we explain what paradigms are and why Lean management represents a paradigm shift. We then apply lessons learned from successful paradigm shifts in other fields to suggest what the Lean Construction community can do to nurture an industry-wide paradigm shift to Lean. By discussing this topic, we hope to bring the concept of paradigms to a position of greater prominence in the Lean discourse, in part helping Lean enthusiasts to understand why those mired in the traditional management paradigm just can't seem to "get it" no matter how hard the latter group tries to explain.
\end{abstract}

\section{KEYWORDS}

Lean construction, Lean management, paradigms, paradigm shift.

\section{INTRODUCTION}

The term "Lean" was coined thirty years ago (Krafcik 1988), and the turn of the century (now eighteen years past) saw two seminal doctoral theses that brought Lean to the world of construction (Ballard 2000; Koskela 2000). And yet, even today, despite Lean repeatedly having proven advantages, the vast majority of construction projects are

1 PhD Student, Faculty of Civil and Environmental Engineering, Technion - Israel Institute of Technology, Haifa, Israel, shmuel.korb@technion.ac.il

2 Research Director, Project Production Systems Laboratory, University of California Berkeley, mailto:ballard@ce.berkeley.edu 
conducted using traditional styles of management that predate Krafcik's work(Azari et al. 2014). Why? In no small part, due to paradigms.

Paradigms are the filter through which one sees the world(Ballard et al. 2011; Ballard and Howell 2003). Facts have no objective truth on their own; they are given meaning through the lens of one's paradigm. This is the reason two people from opposite ends of the political spectrum can read the same news article but draw vastly different conclusions as to its veracity and what actually transpired. Lean Construction enthusiasts have often struggled in their conversations with construction professionals steeped in the old ways of doing things, often wondering how it is possible to confront the proven benefits of Lean with apathy and disbelief. The reason that the uninitiated are able to brush aside the claims of Lean are that in their prevailing paradigm, the claims are unbelievable and thus false. Cut project delivery times in half? Impossible. Bring projects in on time and under budget? Can't be done.

Lean, with its dependence on the twin pillars of Continuous Improvement and Respect for People (Korb 2016) is very much a paradigm shift from the current practice in construction, since it requires whole new patterns of thinking and behaving, not merely small tweaks to existing practice. As identified by Gehbauer et al. (2017), the traditional paradigms must be made explicit and addressed for Lean Construction to flourish.

In this paper, we will discuss what paradigms are and what is currently known about them, in order to bring this issue to greater exposure in the Lean Construction community. It is the hope of the authors that by making people sensitized to the concepts they can be more aware of and informed by them as they continue their work in advancing the cause of Lean in the AEC industry. We then suggest some possible tactics for overcoming the prevailing paradigms that the Lean Construction community can undertake as a whole, concluding on a note of hope for the future.

\section{WHAT ARE PARADIGMS?}

It was Kuhn's book“ The Structure of Scientific Revolutions"(2012) which brought the concept of paradigms to widespread attention. Kuhn's focus was on the history of science, looking at how new developments are made and well as breakthroughs, and thus the main paradigms he focused on were scientific in nature. In his view, paradigms are the governing models in which scientists try to solve problems, such as the Ptolemaic geocentric model of planetary motion. Under this model, astronomers were forced to develop increasingly complex "epicycles" to explain the "aberrant" behavior of the heavenly bodies, since those were the problems they faced and the underlying model in which they understood the solar system to operate. When the Copernican heliocentric model was first presented, to someone who had labored for years in perfecting epicycles, it could only be seen as a farce (particularly, as Kuhn notes, since it didn't offer any more reliable predictions than the existing well-honed Ptolemaic model). Thus paradigms function (inadvertently) as constraints preventing the transitioning to new modalities of thought, in as much as they anchor one's beliefs about the realm of the possible.

Kuhn (2012) defined paradigms as follows: "Universally recognized scientific achievements that, for a time, provide model problems and solutions for a community of 
researchers." Here, his focus on paradigms in the scientific context is clear, but the points of universal recognition and models for framing problems and solutions are applicable in many other contexts.

In Kuhn's view, rival paradigms are "incommensurable"; that is, one paradigm cannot be understood through the lens (the concepts and terminology) of the other. This bears strong similarity to the discourse disconnect between the Lean Construction advocate and the traditional construction professional referenced in the introduction; the claims of what improvements Lean is capable of bringing seem fanciful for someone who is party to the previous paradigm.

Kuhn identified five phases in the course of paradigm development and renewal, as shown in Table 1.

Table 1: Kuhn's five phases of paradigm development

\begin{tabular}{cc}
\hline Phase & Description \\
\hline 1 & Pre-Paradigm \\
2 & Normal Science \\
3 & Crisis \\
4 & Paradigm Shift \\
5 & Post-Revolution (Return to Normal Science) \\
\hline
\end{tabular}

Kuhn saw the development of science as alternating between the periods of "normal science", in which incremental improvements are made to the body of knowledge that is in line with the current paradigm, and "paradigm shift," the more tumultuous periods were the old and new paradigms themselves are in conflict.

Returning to the realm of Lean Construction, we can roughly draw parallels of these five steps in light of the history of construction management.

Phase one is the pre-paradigm stage. This perhaps was the prevailing mode of construction management for millennia of human development, when construction was primarily of dwellings and simple structures for storage and agriculture. There was no need to manage projects; they were simply built.

Phase two is the development of a paradigm, brought about by the coalescence of problems that can't be solved in the pre-paradigm state. Going back to antiquity, there were examples of large and ambitious construction projects (such as the Seven Wonders of the Ancient World and their contemporaries) which were massive undertakings requiring the coordination of hundreds if not thousands of designers and builders. These no-doubt required the development of at least a rudimentary paradigm of construction management. And since then, through to the modern day, there has been a gradual building upon the practice, step by incremental step, similar to Kuhn's "puzzle solving".

Phase three - crisis - is arguably where the industry stands today: performance results are lagging expectations. The Egan Report (1998) highlighted the deficiencies and called 
for change. While other industries have improved their productivity over the years, construction has been marching in place or even retreating. Persistent problems exist that cannot be solved with the existing tools. Kuhn called these "anomalies," and an accumulation thereof indicates that a new paradigm may be required to address them.

The fourth phase is the paradigm shift itself, when the new paradigm arises, and after a period of penumbra, eventually trumps the old. In the case of Lean Construction, the hope is that this phase has begun. New exemplars of the Lean paradigm are bearing fruit, addressing some of the anomalies that the previous paradigm is not capable to dealing with.

In Kuhn's final phase, the new paradigm takes root and becomes dominant and pervasive, bring the cycle back to the second phase, normal science. Lean Construction has some ways to go before reaching this zenith.

\section{WHY ARE PARADIGMS A PROBLEM FOR LEAN CONSTRUCTION?}

Understanding what paradigms are, it is now possibleto direct attention to whyparadigms are a problem in the context of advancing Lean Construction.

Since paradigms are so pervasive and all-encompassing for those who hold them, it is sometimes not apparent to the holder that they are no more than models they have chosen; models that might not be the best or even correct in all aspects. The paradigm is accepted at face value as common knowledge or tautology. Consider the list of paradigms or paradigm-reflecting statements from traditional construction management that appear in Table 2; how widespread are these in the industry? And to what extent are they demonstrably true?

The answers to the above questions are as follows:

1. These statements, even if only as unspoken beliefs, are indeed widespread in the industry. Construction professionals in the traditional paradigm default to behaving in accordance with them when under pressure, believing them to be true.

2. On nearly every point, counter examples or at least counter arguments can be brought to disprove them.

Taken together, these points would seem to represent a conflicted state; how is it possible that these beliefs are both widely held and also not true? The answer is called confirmation bias. Confirmation bias (Plous 1993) is a tendency to accept evidence as true when it aligns with a pre-held conviction (such as a paradigm) and reject it as an error or inconsequential anomaly when the evidence is at odds with the pre-existing belief. This is exactly why no matter how many successful IPD projects or Lean Construction success stories one shares with a traditional thinker, they will be rejected as either completely false or as having some extenuating circumstance that is both uncommon and irrelevant to the majority of construction practice. Or in other words: "We're different." 
Table 2: Paradigms in traditional construction management (Ballard et al. 2011)

Paradigm
Trust is for suckers.
Win-win is an illusion. What counts is that I win.
You can manage projects by managing contracts.
Risk is managed when transferred to someone else.
If you pay least price for each part of a project, you pay
least price for the project.
Management by results yields the best results.
Variation in work flow is from external causes.
Resource utilization trumps project flow.
Control starts with identifying a negative variance between
DID and SHOULD.
Social factors are interesting, but don't really matter.

Thus while it might be conceivable to overturn some of the statements in Table 2 with statistical studies (for example, tracking the causal drivers of total project price in projects with and without least-cost subcontractor selection), the effort would still likely fall on deaf ears, or ears shielded by the "hearing protection" that only a paradigm can offer.

Barker (1993)referred to the inability to take constructive action in the face of new realities "paradigm paralysis" in the sense that the situational blindness conformance to a paradigm demands will ultimately lead to sclerosis exactly when action is needed. He cites multiple examples of this happening in different industries, such as the Swiss dominance of the watch industry prior to the advent of the quartz watch. The quartz timekeeper was invented in Switzerland, but it had no place in their world of finely crafted and intricate mechanisms. The Swiss were not able to capitalize on the new technology since they didn't accept it, ultimately leading to them losing out on the majority of the watch market to Japanese companies who were not married to centuries of mechanical chronometer history. Another example concerns the development of many elements of the Graphical User Interface (GUI) by Xerox, who saw no future in what would go on to change the face of computing. Time after time, industry leaders are unable to adopt change, even when it is staring them in the face or they have even had a hand in developing it.

In construction, a complicating factor is the fragmented nature of the industry (caused in no small part by the reliance on subcontracted labor, which is another symptom of an underlying paradigm)which can constitute a barrier to spreading new ways of thinking and acting, since any one company represents such a small portion of both the market and 
the total value chain, one that must interface with the existing other parts of the value chain all of which are used to working in the prevailing methods.

Thus we have shown that not only are paradigms real, they are a real problem when it comes to implementing Lean in the field of construction.

\section{WHAT CAN BE DONE?}

What, then, is to be done? Given that the transition to Lean thinking involves a paradigm shift, and that paradigms are rarely shifted and only with great difficulty, in what ways can the Lean Construction community act to advance the adoption of Lean in the entrenched AEC industry? This section suggests a few possible paths of action, though it is the hope of the authors that once the centrality of paradigm-based thinking comes to light, other strategies will present themselves.

The following strategies are in line with those developed by the second author and Greg Howell and for the Lean Construction Institute shortly after its formation in 1997, which included the following elements:

- Change the vocabulary-from managing contracts to managing production.

- Work with early adopters to make them killer companies in their markets.

- Look for owners willing to embrace lean and help them help their suppliers.

\section{GET THE WORD OUT}

With any new concept or product, there will always be the "innovators"(Rogers 2003) who are willing to try it out primarily because they are neophytes. The innovators represent a fringe of the population who are willing to adopt the innovation before it has been fully proven. In other words, they don't need to have their paradigm shifted to be willing to try out Lean; the promise of benefit is all they need to give it a shot.

With this understanding in mind (namely, that there are people who are inclined to be innovators), the question is how to reach them. The message must be out there so that they can find it, if they are to adopt it. As Lean enthusiasts, at a minimum, we must be looking for how can we give the subject greater exposure. By holding the flag high, people can find Lean. It is specifically those who are willing to listen who are the ones to focus on.

Once they are in the door, it becomes possible to present the rational case of Lean. Arguments about the benefits of Lean and evidence to back up those claims can be presented. Likewise, if it possible to identify common objections to the claims of Lean and present rebuttals, it will make it all the more possible to undercut the traditional approaches, at least for those people who are open-minded and not already invested in the pre-existing paradigm. The hope is that for these members of the population, an accumulation of evidence will have an impact, perhaps in conjunction with having an experience that is anomalistic to the traditional paradigm.

Practically speaking, this means highlighting the successful case studies of companies who have succeeded with Lean, continuing to generate a body of knowledge such as the IGLC has done and continues to do, and making inroads in other forums where construction experts gather. 


\section{EDUCATE THE NEXT GENERATION}

Max Planck, the theoretical physicist and Nobel laureate, weighed in on the subject of paradigms in a now-famous quote: "A new scientific truth does not triumph by convincing its opponents and making them see the light, but rather because its opponents eventually die, and a new generation grows up that is familiar with it." If one harbors the notion that it is possible to convince others, it may lead to effort wasted on trying to convince those who are set in their ways, which in turn may retard progress elsewhere. If instead the advice of Planck is heeded, the lost causes may be recognized for what they are.

In other words, a more effective use of energy for those seeking to make the case for a new paradigm such as Lean, rather than engaging in fruitless arguments with industry stalwarts who have years of experience backing up their convictions, is to focus on the next generation of AEC professionals, namely those currently studying the field in universities.

Currently, there is a paucity of Lean Construction discussion in undergraduate civil engineering education; when construction management is taught, it tends to highlight the more traditional approaches, relegating Lean Construction to graduate-level courses. If Lean Construction were to occupy more of a focal point of the studies, students would be exposed to the concepts and the successful examples of Lean implementations while they are still young, before they go out to the real world of practice. In so doing, it may be possible to color the way they interpret the realities they then encounter, at the very least opening them up to nagging questions like "isn't there a better way?". By creating a generation of civil engineers growing up with Lean, it may be possible to cement a "new normal" reference frame for them as they join the ranks of industry.

This suggestion is complicated by the dearth of assessment criteria for academic programs, specifically measures of process (the quality of the Lean content being instructed) and outcomes (how much of an impact is made on the students), and as such the development of relevant metrics is an area for future work. In general, simulations and hands-on learning exercises can be more effective than merely spouting lists of the benefits. This is one of the reasons "going to Gemba" can be so powerful; it is there that the messages hit home in a visceral way. Sacks et al. (2018, ch. 9) relate the story of how the leadership of a construction company "learned to see" by spending time on the work face, out of the office, merely looking and observing examples of waste.

One risk with this education-focused model is that young civil engineers might not be gaining their true education in the classroom, but rather only once they get out into the field. There, they will likely be schooled if not by hard knocks then at least by those of the older generations. And the lessons they will be taught will likely be those of the traditional paradigm. So it will be necessary to monitor the long-term effectiveness of the Lean "vaccine" that will be administered to these bright young minds.

Encouragingly, there are signs of interest on the part of the next generation, who are trying to "pull" the information and education they need. The second author of this paper, through his exposure in developing the Last Planner® System (Ballard 2000) and his years of involvement in the Lean Construction community as an educator and thinker, 
receives requests from students (both current and former) from around the world to assist them as they work to learn more about Lean Construction and expand its deployment. Often they are hampered by a lack of local expertise (both on the academic side and the professional), leading to a further suggested path: make Lean Construction coaching available to people around the world who don't have access to the teachings or insights. The "coaches" in this scenario could be members of the IGLC community (itself a wellestablished world-wide network) who volunteer their time to assist and enable those sparks of interest wherever they may be kindled.

\section{CREATE MARKET PRESSURE}

A third tactic may be to attract and interest the owners of construction projects, and explain to them the benefits that Lean can bring to their projects. By informing the customers of construction services, it may be possible to change the market demand to the point where Lean becomes a requirement on the part of suppliers. This parallels some examples of the adoption of Building Information Modeling (BIM): in markets where large or influential customers demand BIM, the local suppliers are forced to develop BIM competencies if they wish to compete for business. Likewise in the Lean construction world, as evidenced by the experience of Sutter Health. Sutter has long been a pioneer in Lean Construction, and they now require Lean as a threshold criterion for their contractors.

At the same time, the risk of this kind of "top-down" customer-driven adoption scenario is that Lean becomes just another box to be checked without fully understanding it or integrating it into the organization's culture. This can sometimes be seen with BIM where companies will have an out-sourced BIM capability in order to meet contract demands but continue to work in-house the way they always have. In the same manner, for companies wishing to reap the benefits of Integrated Project Deployment (IPD), it is not sufficient to merely have an IPD contract in place; the ways of working and the manner in which the relationships are built among the project participants have to be fundamentally different from the old ways of working.

Likewise, there are situations where the marketing materials of a company extolling their Lean successes and how much they have implemented outpace the reality of their daily practice in the Gemba. As in any Lean implementation in the AEC field or beyond, company leadership needs to understand that their companies won't change until they do. And yet, requirement on the part of customers can often be an effective catalyst for change; only if they are forced will some people embrace something new. Thus if the customers can be reached and their desire or outright demand for Lean, there is a greater chance for wider adoption through market pressure. One stalwart in a market can lead to horizontal spread in that local market, since as customers they can stipulate the process (and not just the product) required.

One way to reach customers continues to be the Lean Construction Institute (LCI) annual congress. In its most recent incarnation, there were 1,500 attendees. The attendance rate has seen a steady $15 \%$ growth year-over-year in last 5 years, which means new people from the industry are becoming interested and getting exposed. These conferences serve as wonderful platforms for getting the word out as discussed above, 
since they highlight successes and address concerns, which can inspire further motivation and interest.

On observation about the LCI congresses is that over time the nature of the conversation has changed, with it now showing signs of maturity. There is a greater focus on the philosophy underlying the Lean approach, whereas earlier focus was more on Lean tools. This is a sign of improvement, since it indicates that the community is touching upon deeper issues beyond the superficial trappings of Lean as they continue their journey to implement Lean. The further they go, the more they will have to relate back, which will work to create a market imperative. At the same time, we need to continue the efforts to educate owners about what to require in the projects to improve their chances of Lean succeeding.

\section{CONCLUSIONS}

This then is a call to action for the Lean Construction community. First, it is imperative that the issue of paradigms is prominent in any outreach efforts, for ignoring their impact increases the chances of failure through not addressing them properly. Second, armed with an awareness of the pervasive and powerful nature of paradigms, we can begin working to change the prevailing winds of the industry. This can be through the strategies identified and described above, or in other innovative ventures designed to address this key topic.

On the one hand, the message of this paper has been somewhat pessimistic: by and large it is not possible to change people's paradigms, so don't even bother trying. Yet on the other, there is a message of hope. As Planck observed, revolutions can take a generation or more. So while a perceived lack of progress when measured in absolute measures of market penetration can be disheartening for innovators, the numbers may bely what may prove to be long-term exponential growth. In other words, there is not yet cause to lose hope or become discouraged by a slow pace of adoption of Lean. Change does happen, and in the case of Lean Construction, it is worth the effort. As advocates, it is incumbent upon us to be absolutely persistent but also patient. It may be hard, but it is the right choice to make. There is a small part of the population that is less tethered to presuppositions and more open to wonder and exploration - these are the ones that need to be reached. In turn, this makes possible the creation of market pressure. The cold facts of declining market share, revenues, or profit margin work wonders as paradigm solvents.

\section{REFERENCES}

Azari, R., Kim, Y.-W., Ballard, G., and Cho, S.-K. (2014). "Starting From Scratch: A New Project Delivery Paradigm.” American Society of Civil Engineers, 2276-2285.

Ballard, G., and Howell, G. A. (2003). "Competing Construction Management Paradigms." American Society of Civil Engineers, 1-8.

Ballard, G., Kim, Y.-W., Azari, R., and Cho, S. (2011). Starting from scratch: A new project delivery Paradigm. Construction Industry Institute, Austin, TX.

Ballard, H. G. (2000). "The Last Planner System of Production Control." The University of Birmingham, Birmingham, UK. 
Barker, J. A. (1993). Paradigms: the business of discovering the future. HarperBusiness, New York, NY.

Egan, J. (1998). Rethinking Construction: Report of the Construction Task Force. HMSO, London, 38.

Gehbauer, F., Ballard, G., and Leonova, M. (2017). "How Research Can Help Transform the Construction Industry." 25th Annual Conference of the International Group for Lean Construction, Heraklion, Greece, 293-300.

Korb, S. (2016). "'Respect for People' and Lean Construction: Has the Boat Been Missed?" 24th Annual Conference of the International Group for Lean Construction, Boston.

Koskela, L. (2000). "An Exploration towards a Production Theory and its Application to Construction." Dissertation for the degree of Doctor of Technology, Helsinki University of Technology.

Krafcik, J. F. (1988). "Triumph of the Lean Production System.” MIT Sloan Management Review, 30(1), 41-51.

Kuhn, T. S. (2012). The structure of scientific revolutions. The University of Chicago Press, Chicago ; London.

Plous, S. (1993). The psychology of judgment and decision making. McGraw-Hill series in social psychology, McGraw-Hill, New York.

Rogers, E. M. (2003). Diffusion of innovations. Free Press, New York.

Sacks, R., Korb, S., and Barak, R. (2018). Building Lean, Building BIM: Improving Construction the Tidhar Way. Routledge, New York, NY. 